\title{
Comparison of iron (III) and alum salt on ultrafiltration membrane fouling by alginate
}

\author{
Baiwen Ma ${ }^{\mathrm{a}, \mathrm{b}}$, Wenzheng $\mathrm{Yu}^{\mathrm{a}}$, Huijuan Liu ${ }^{\mathrm{a}}$, Jiuhui $\mathrm{Qu}{ }^{\mathrm{a}, *}$ \\ ${ }^{a}$ Key Laboratory of Drinking Water Science and Technology, Research Center for Eco-Environmental Sciences, Chinese Academy of Sciences, Beijing 100085, China \\ ${ }^{\mathrm{b}}$ University of Chinese Academy of Sciences, Beijing 100049, China
}

\section{H I G H L I G H T S}

- Sodium ions exacerbate the fouling caused by alginate coagulated with iron/alum salt.

- Calcium ions mitigate the fouling caused by alginate coagulated with iron/alum salt.

- Flux decline is depended on the ratio of sodium ions to calcium ions in the system.

- Alum salt behaves better than iron salt when membrane fouling is caused by alginate.
GRAPHICAL A B STRACT

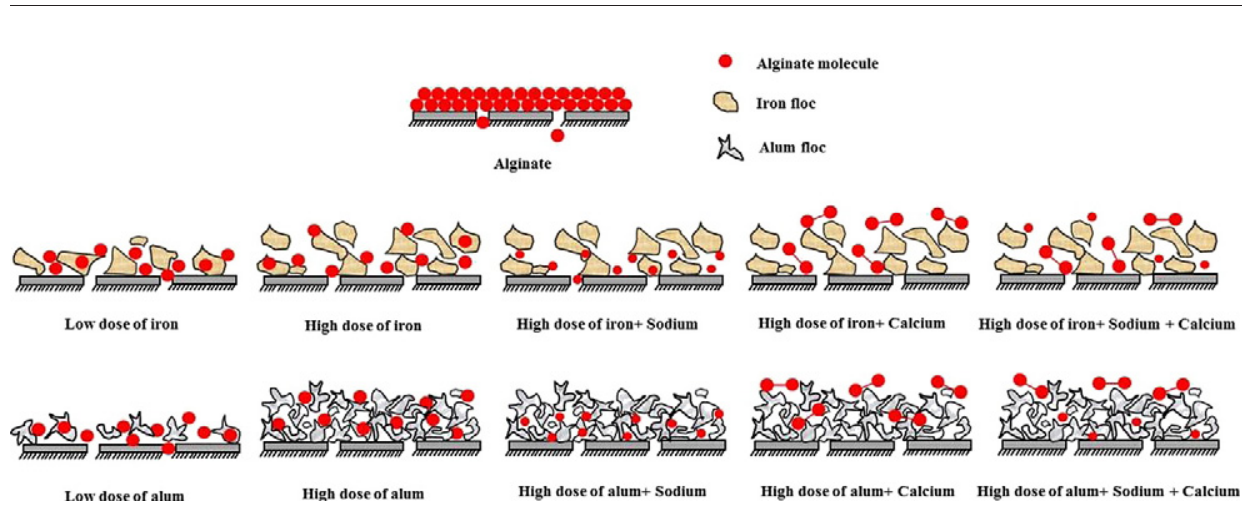

\section{A R T I C L E I N F O}

\section{Article history}

Received 12 May 2014

Received in revised form 1 October 2014

Accepted 3 October 2014

Available online 22 October 2014

\section{Keywords:}

Ultrafiltration

Flux decline

Alginate

Iron (III) chloride hexahydrate

Aluminum chloride

\begin{abstract}
A B S T R A C T
Compared with humic acids or proteins, polysaccharides usually cause more severe flux decline. Here, the ultrafiltration (UF) membrane fouling caused by alginate coagulated with iron (III)/alum salt was investigated in the absence/presence of ionic strength $(\mathrm{NaCl})$, calcium ions and their combinations in the system. The results showed that flux decline was significantly reduced only in the presence of high dose of iron/alum salt. With increasing ionic strength, the membrane flux caused by alginate coagulated with high dose of iron/alum salt was decreased, while that was dramatically increased in the presence of calcium ions. When ionic strength and calcium ions were presented with high dose of iron/alum salt, flux decline was determined by the ratio of sodium ions to calcium ions. Alum salt behaved much better than iron salt on reducing membrane fouling with/without ionic strength, calcium ions and their combinations in the solution. Membrane flux was high at coagulation conditions that resulted in low concentration of alginate after filtration, which was in the presence of high dose of alum salt, especially in combination of calcium ions.
\end{abstract}

(c) 2014 Elsevier B.V. All rights reserved.

\section{Introduction}

Ultrafiltration (UF) membranes have been increasingly used in water treatment, mainly owning to the superior and stable permeate quality even in the conditions of variable feed-water characteristics

\footnotetext{
* Corresponding author. Tel.: +8610 62849160; fax: +861062923558

E-mail address: jhqu@rcees.ac.cn (J. Qu).
}

[1]. However, membrane fouling is the main limitation for a broader application of membrane technology [2,3]. Polysaccharides, which dominate the extra-cellular polymeric substances (EPS), are produced by microorganisms [4]. In comparison with the fouling behavior of humic acids or proteins, polysaccharides could cause much more serious flux decline in natural waters due to its wide molecular weight distribution $[5,6]$. Alginate is a hydrophilic polysaccharide and has been extensively studied as a model by many researchers $[1,7,8]$. It consists of a linear 
copolymer with varying proportions of 1,4 -linked $\beta$-D-mannuronic acid, C-5 epimer and $\alpha$-L-guluronic acid [4].

The physical properties of alginate are influenced by ionic strength $(\mathrm{NaCl})$ [9]. At higher ionic strength, the electric double layer around the negatively charged alginate molecules was compressed [10]. As a result, alginate molecules become more coiled due to the reduced electrostatic repulsion [11,12]. Up to now, many studies have reported that alginate could accelerate membrane fouling at high ionic strength, owning to more chances of alginate molecules depositing onto the membrane surface even blocking the membrane pores [13,14].

In addition to decreasing the particle size of alginate molecules in the presence of high ionic strength, calcium ions are well known as "bridging agents" with alginate molecules for many years, where calcium ions bind preferentially with carboxylic functional groups and the adjacent alginate molecules are linked $[15,16]$. It has been found that membrane flux can be improved by increasing the concentration of calcium ions, which is possibly due to the larger particle size (resulting in a lower resistance) or a highly permeable alginate gel layer induced by calcium ions [17-19].

Coagulation is the most common process to remove turbidity and natural organic matter (NOM) in drinking or waste water treatment, and iron/alum salts are widely used as coagulants for pretreatment, which is advantageous on improving permeate flux [20-22]. The extent of improvement on the performance of membrane filtration is greatly dependent on the properties of coagulants, dosages, pH, etc. [23,24]. Barbot et al. [24] presented that alum species played an important role on the characteristics of coagulant flocs, which could influence the behavior of the downstream membrane filtration. Yu et al. [25] found that a much lower trans-membrane pressure (TMP) was caused by alum salt compared to that induced by iron (III) salt in the UF system, and Konieczny et al. [26] demonstrated that membrane fouling was much more reduced by $\mathrm{Al}_{2}\left(\mathrm{SO}_{4}\right)_{3}$ than that by $\mathrm{Fe}_{2}\left(\mathrm{SO}_{4}\right)_{3}$ or $\mathrm{FeCl}_{3}$ in the "in-line" coagulation-ultrafiltration hybrid process. According to Qiao et al. [27], $\mathrm{FeCl}_{3}$ was better for membrane fouling in a large-scale UF process in comparison with polyaluminum chloride ( $\mathrm{PACl})$.

Herein, in order to understand the different performance of UF membrane caused by alginate in the presence of iron/alum salt, iron (III) chloride hexahydrate (iron salt) or aluminum chloride (alum salt) was added into the feed. To further probe into the fouling mechanism, sodium chloride, calcium chloride and their combinations were added into the solution in the presence of iron salt or alum salt. The corresponding membrane flux decline and the alginate concentration after filtration were systematically investigated. In addition, a schematic model was proposed based on the findings from this study to better illustrate the fouling phenomena.

\section{Experimental methods}

\subsection{Materials}

All chemicals were analytical reagent except specific illustration. Deionized (DI, Millipore Milli-Q) water was used to prepare stock solutions. Sodium alginate, sodium chloride, iron (III) chloride hexahydrate and aluminum chloride were obtained from Sinopharm Chemical Regent Co., Ltd (China). A stock solution of sodium alginate was prepared at a concentration of $10 \mathrm{~g} / \mathrm{L}$ using DI water. Sodium alginate working solution was used within one week to prevent the growth of microgram. The solution was stored in prewashed glass bottle in the dark at $4{ }^{\circ} \mathrm{C}$ and was brought to room temperature immediately prior to use.

\subsection{Ultrafiltration experiments}

The polyvinylidene fluoride (PVDF, Ande membrane separation technology \& engineering (Beijing) Co., Ltd, China) flat sheet UF membrane $(100 \mathrm{kDa})$ was used in all experiments. Fresh membranes were placed in DI water for $24 \mathrm{~h}$ to remove impurities. All membranes were filtrated with $300 \mathrm{ml}$ DI water first in order to keep the membrane flux constant. The stirred cell (Millipore, Amicon 8400) was driven by nitrogen gas and the pressure was maintained stable (0.1 MPa) during filtration. $\mathrm{J} / \mathrm{J}_{0}$ as a function of time was used for the flux variation from the stirred cell experiments, where $J_{0}$ was the initial membrane flux.

During the test, $\mathrm{pH}$ of the final solution was maintained at 7.0 by prior addition of a predetermined amount of $0.1 \mathrm{M} / 1 \mathrm{M} \mathrm{NaOH}$. To understand the membrane fouling under different conditions, sodium chloride, calcium chloride and their combinations were added. Then $\mathrm{NaHCO}_{3}$ and iron/alum salt stock was diluted into the feed. Afterward $10 \mathrm{mg} / \mathrm{L} \mathrm{SA}$ was formed by adding the corresponding stock solution to working solution. Rapid mixing speed of $200 \mathrm{rpm}$ was maintained for $1 \mathrm{~min}$ and slow mixing speed of $50 \mathrm{rpm}$ was maintained for another 14 min to allow floc growth. All experiments were conducted at room temperature.

\subsection{Jar test}

A 0.5 L beaker with a flocculator device (ZR4-2, Zhongrun, China) was used for the jar test, which can provide comparative information. The selected dose of iron salt or alum salt $(1.2 \mathrm{mM})$ was added with solution $\mathrm{pH}$ at 7.0. The stirring speed was simultaneously increased to $200 \mathrm{rpm}$. The speed was maintained for $1 \mathrm{~min}$, and then reduced to $50 \mathrm{rpm}$ for 14 min to allow floc growth to occur. Dynamic floc size and fractal dimension $\left(D_{\mathrm{f}}\right)$ were measured by a laser diffraction instrument (Mastersizer 2000, Malvern, UK) as the coagulation and flocculation processes proceeded. Floc size measurement was taken every $30 \mathrm{~s}$ and logged by computer while fractal dimension was measured by small-angle light scattering. Detailed method has been described extensively by other studies [28,29].

\subsection{Analytical measurements}

Membrane flux was recorded by data logger. $\mathrm{pH}$ was tested by Orion pH Benchtop while zeta potential was measured by Nano particle sizing \& Zeta potential analyzer (Delsa Nano C, Beckman Coulter Ltd, USA). Membrane pore size was analyzed by IB-FT, GmbH (POROLUX 1000, Germany). Images of the surface of the fouled membrane were obtained using scanning electron microscopy (SEM) which was carried out with a JSM-7401F Field Emission equipped with a cold Field Emission Gun in SEI mode at $3 \mathrm{kV}$ accelerating voltage (JEOL Ltd., Tokyo, Japan). Total polysaccharide concentration was measured by the phenol sulfuric acid method [30].

\section{Results}

\subsection{In the presence of iron/alum salt}

To investigate the flux decline caused by alginate coagulated with iron/alum salt, different doses of iron/alum salt were added into the feed. The flux-decline curves obtained during each fouling run are compared with the alginate concentration after filtration in Fig. 1. A much lower flux decline caused by alginate was observed in the presence of $1.2 \mathrm{mM}$ iron salt or alum salt compared to that in the presence of $0.1 \mathrm{mM}$ salt. Similar trend of the concentration of alginate after filtration was also found (Fig. 1b). The concentration of alginate after filtration was $1.83 \pm 0.19 \mathrm{mg} / \mathrm{L}$ in the absence of iron salt or alum salt, while that was decreased with increasing the dose of coagulants in the feed, especially for the $1.2 \mathrm{mM}$ alum salt (alginate concentration after filtration was $0.45 \pm 0.07 \mathrm{mg} / \mathrm{L}$ ).

Many studies show that pore blockage of UF membrane plays an important role in the case of fouling by polysaccharides [1,31]. It is reported that the diameter of alginate molecule is in the range of $50-137 \mathrm{~nm}$ $[32,33]$, while the average pore diameter of the UF membrane used in our experiment was $43.8 \pm 5.3 \mathrm{~nm}$. Thus, adsorption and pore blocking 
(a)

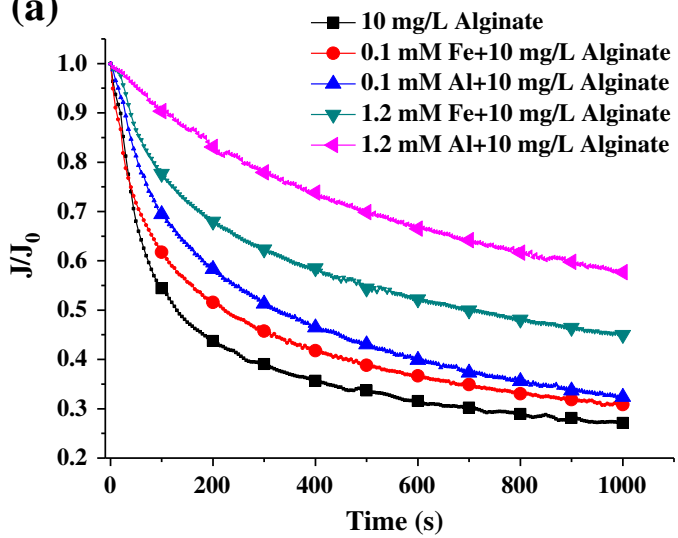

(b)

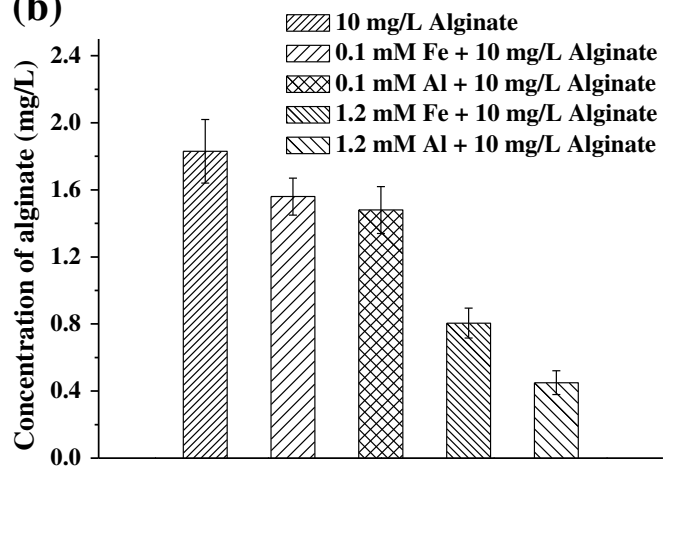

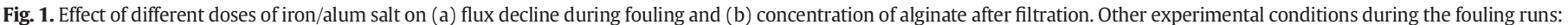
$\mathrm{pH}=7.0$.

were occurred during the filtration, leading to severe membrane fouling in the absence of coagulants (final $\mathrm{J} / \mathrm{J}_{0}=0.27$ ). When the dose of iron salt or alum salt was low $(0.1 \mathrm{mM})$, the chance of alginate molecules depositing onto the membrane surface was still large because most alginate molecules could not be "captured" by the iron flocs or alum flocs. As a result, the concentration of alginate after filtration was only a little lower than that in the absence of iron/alum salt. When high dose of coagulant was applied $(1.2 \mathrm{mM})$, more alginate molecules could be adsorbed or "trapped" by the iron/alum flocs. Thus, membrane flux was increased and the corresponding concentration of alginate after filtration was low (Fig. 1b). It was also observed that alum salt behaved better than iron salt during the filtration.

Fig. 2 shows the surface morphology of membrane after the filtration of $10 \mathrm{mg} / \mathrm{L}$ alginate coagulated with $1.2 \mathrm{mM}$ iron salt or $1.2 \mathrm{mM}$ alum salt. It was clearly shown that the cake layer formed by iron salt coagulating with alginate was less compact compared with that formed by alum salt, indicating that more chances of non-captured alginate molecules getting to the membrane surface and passing through the membrane.

\subsection{In the presence of iron/alum salt with ionic strength}

Owning to the dramatic variation of the flux decline caused by alginate in the absence/presence of $1.2 \mathrm{mM}$ iron salt or alum salt (Fig. 1a), the dose of $1.2 \mathrm{mM}$ was chosen. The influence of ionic strength (calculated as $\mathrm{NaCl}$, the same below) on the flux-decline behavior during alginate fouling in the presence of $1.2 \mathrm{mM}$ iron/alum salt and the corresponding concentration of alginate after filtration are presented in Fig. 3. It was shown that the flux decline as well as alginate concentration after filtration became more substantial with increasing ionic strength.

These results can be ascribed to the following reasons. Firstly, the electric double layer around negatively charged alginate molecules was compressed at higher ionic strength, resulting in the decreased electrostatic repulsion between alginate molecules and membrane surface [6,11]. Secondly, alginate molecules became more coiled at higher ionic strength because of the reduced interchain electrostatic repulsion, reducing the size of the molecules in solution [12]. Thus, more alginate molecules could not be "captured" by the $1.2 \mathrm{mM}$ iron flocs or alum flocs. It was easier for the coiled alginate molecules getting to the membrane surface even blocking the membrane pores. In contrast, the relatively strong electrostatic repulsion between alginate molecules and the membrane surface prevented the alginate molecules getting to the membrane surface and a lower concentration of alginate after filtration was found. Similar trends of accelerating membrane fouling by increasing ionic strength have been observed in other studies [9,11]. They found that the membrane flux decline was increased with increasing ionic strength when there was alginate alone even when there were humic acids alone. In addition, the membrane flux decline caused by alginate coagulated with $1.2 \mathrm{mM}$ alum salt was still lower than that coagulated with $1.2 \mathrm{mM}$ iron salt in the presence of ionic strength.

\subsection{In the presence of iron/alum salt with calcium ions}

To investigate the flux decline caused by alginate coagulated with $1.2 \mathrm{mM}$ iron/alum salts in the presence of calcium ions, different doses of calcium ions were added into the feed. The permeate flux behavior during fouling and the corresponding measured concentration of
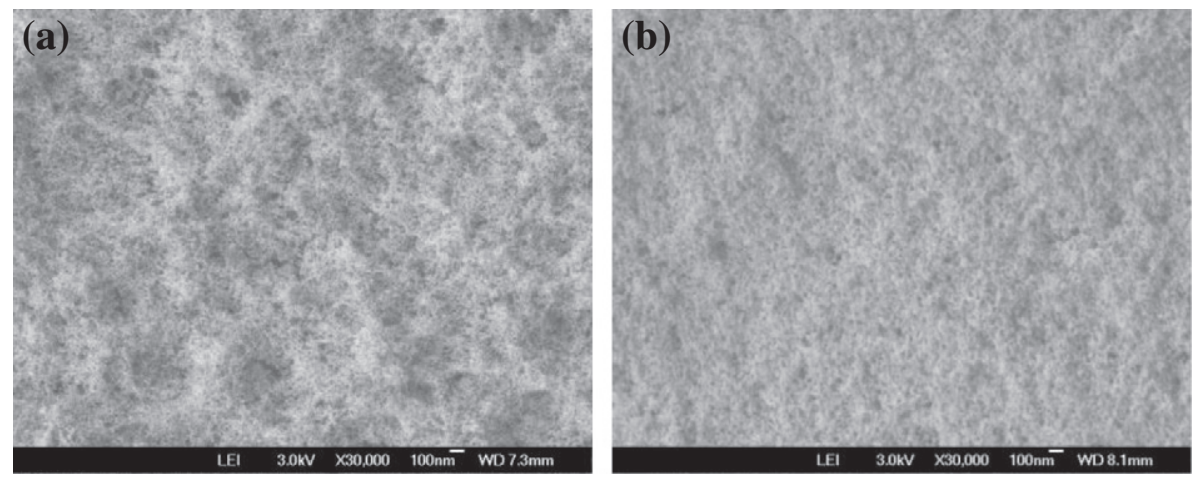

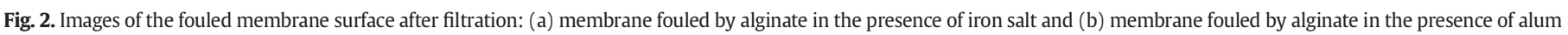
salt. Experimental conditions during the fouling runs: alginate $=10 \mathrm{mg} / \mathrm{L}$, iron salt $=1.2 \mathrm{mM}$, alum salt $=1.2 \mathrm{mM}$ and $\mathrm{pH}=7.0$. 
(a)

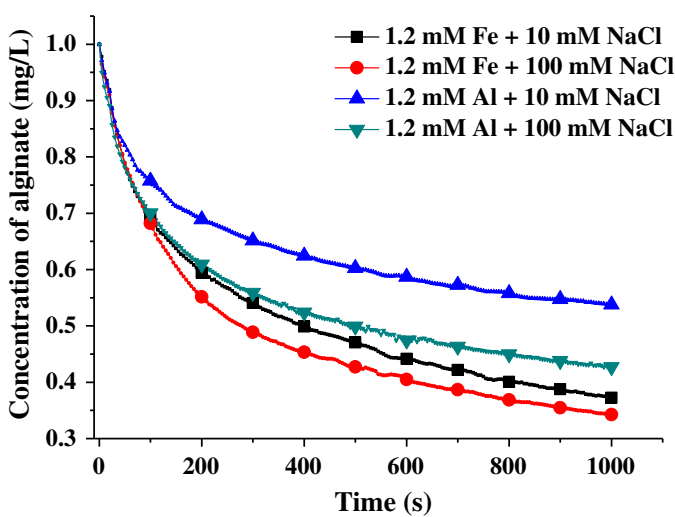

(b)

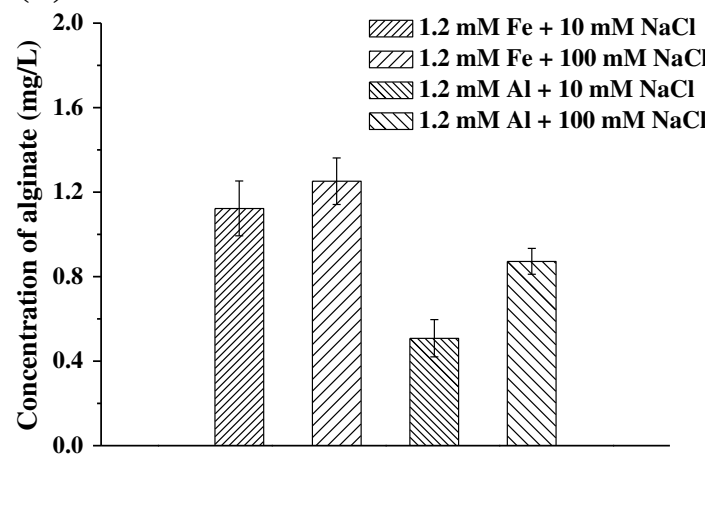

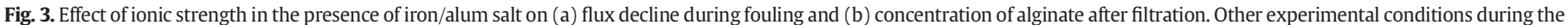
fouling runs: alginate $=10 \mathrm{mg} / \mathrm{L}$ and $\mathrm{pH}=7.0$.

alginate after filtration are presented in Fig. 4. The results showed that the membrane flux caused by alginate coagulated with $1.2 \mathrm{mM}$ iron/ alum salt in the presence of calcium ions was precipitously increased, especially when coagulated with $1.2 \mathrm{mM}$ alum salt. For the $1.2 \mathrm{mM}$ iron salt, the final $\mathrm{J} / \mathrm{J}_{0}$ caused by alginate in the presence of $0.1 \mathrm{mM}$ $\mathrm{Ca}^{2+}$ was increased from 0.29 (alginate alone) to 0.46 , while that caused by alginate in the presence of $1 \mathrm{mM} \mathrm{Ca}^{2+}$ was increased to 0.52 . For the $1.2 \mathrm{mM}$ alum salt, the final $\mathrm{J} / \mathrm{J}_{0}$ caused by alginate in the presence of $0.1 \mathrm{mM} \mathrm{Ca}^{2+}$ was increased from 0.29 (alginate alone) to 0.70 , while that caused by alginate in the presence of $1 \mathrm{mM} \mathrm{Ca}^{2+}$ was increased to 0.75 . Similar trend was found about the concentration of alginate after filtration (Fig. 4b).

Lee et al. $[8,12]$ demonstrated that calcium ions could bind with carboxylic groups, which could form "bridges" between adjacent alginate molecules. Listiarini et al. [17] showed that the average particle diameter of alginate molecules was increased in the presence of calcium ions. Thus, more alginate molecules could be "captured" by the high dose of iron flocs or alum flocs during coagulation and the chance of alginate molecules getting to the membrane surface was decreased dramatically. As a result, membrane flux was significantly improved and the concentration of alginate after filtration was also decreased. Although calcium ions played an important role on the membrane flux in the presence of iron/alum salts, alum salt was still performed much better than that of iron salt.

\subsection{In the presence of iron/alum salt with the combination of ionic strength} $(\mathrm{NaCl})$ and calcium ions

In view of the foregoing observations it was evident that ionic strength could accelerate membrane fouling while calcium ions could mitigate membrane fouling in the presence of iron/alum salts. In order to look further into the fouling behavior caused by alginate coagulated with $1.2 \mathrm{mM}$ iron/alum salts when there was the combination of ionic strength $(\mathrm{NaCl})$ and calcium ions, different ratios of sodium ions to calcium ions were added into the feed (Fig. 5). The results showed that the fouling was more serious with simultaneously increasing the concentration of sodium ions compared to that caused by alginate coagulated with $1.2 \mathrm{mM}$ iron/alum salts in the presence of only $1 \mathrm{mM}$ calcium ions (Fig. 4a). Similarly, the concentration of alginate after filtration was also increased (Fig. 4b).

It has been reported that there is a competition between monovalent and divalent cations for the binding sites on alginate molecules [20,34]. On one hand, alginate molecules became more coiled in the presence of high ionic strength, resulting in more chances of alginate molecules (a)

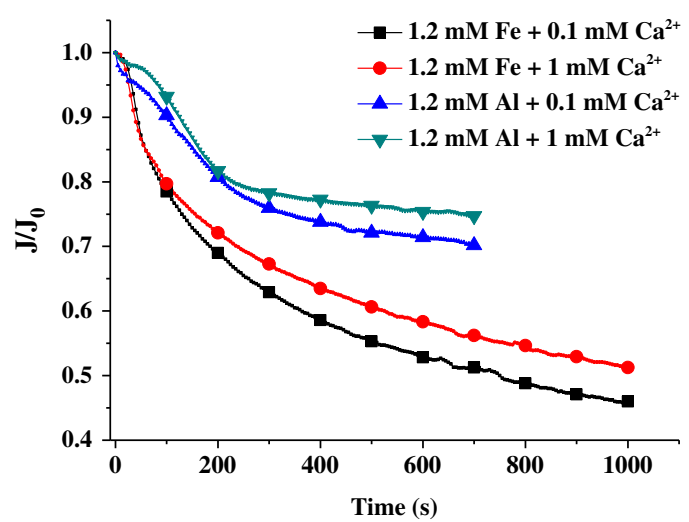

(b)

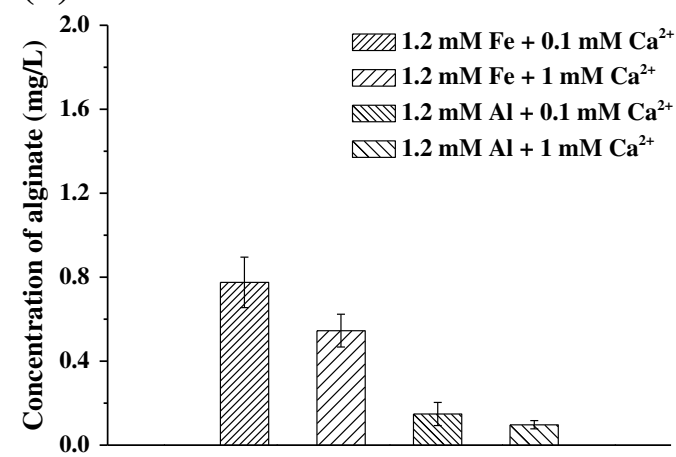

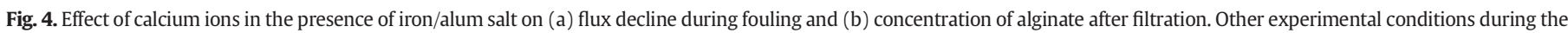
fouling runs: alginate $=10 \mathrm{mg} / \mathrm{L}$ and $\mathrm{pH}=7.0$. 
(a)

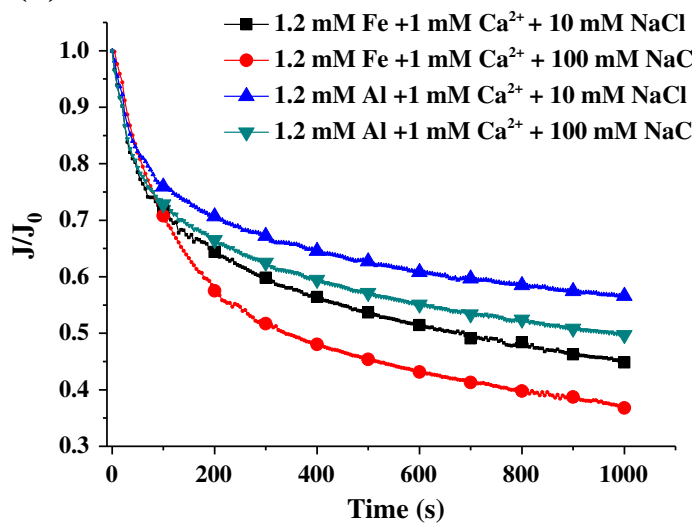

(b)

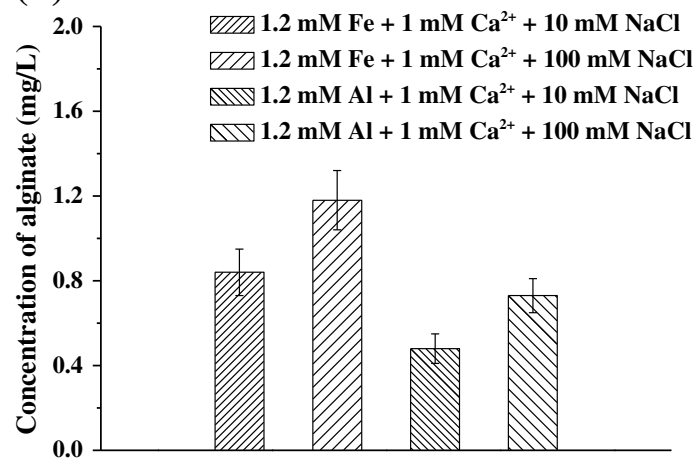

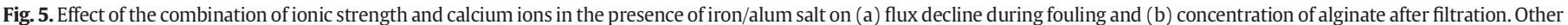
experimental conditions during the fouling runs: alginate $=10 \mathrm{mg} / \mathrm{L}$ and $\mathrm{pH}=7.0$.

depositing onto the membrane surface or blocking the membrane pores. On the other hand, calcium ions bound preferentially with carboxylic groups and formed "bridges" between adjacent alginate molecules, leading to the capture of more alginate molecules by iron/alum flocs. Therefore, the flux decline caused by alginate coagulated with $1.2 \mathrm{mM}$ iron/alum salt in the presence of the combination of ionic strength and calcium ions was more serious than that caused by alginate coagulated with $1.2 \mathrm{mM}$ iron/alum salt in the presence of calcium ions alone, while that was decreased compared to that caused by alginate coagulated with $1.2 \mathrm{mM}$ iron/alum salt in the presence of ionic strength alone. In addition, fouling caused by alginate coagulated with $1.2 \mathrm{mM}$ alum salt was still less serious than that coagulated with $1.2 \mathrm{mM}$ iron salt. The concentration of alginate after filtration was correlated well with the flux decline (Fig. 5b).

\section{Discussion}

Wang and Tarabara [35] demonstrated that pore blocking could cause serious flux decline for the porous microfiltration and ultrafiltration membranes. To understand the fouling mechanism caused by alginate in the presence of iron salt or alum salt, iron chloride hexahydrate or aluminum chloride was added into the solution with/without ionic strength, calcium ions and their combinations. It was shown that alum salt behaved better than iron salt on improving membrane flux.

The diameter of alginate molecules ( 50 to $137 \mathrm{~nm}$ ) was close to the average pore diameter of the UF membrane used (average pore diameter: $43.8 \pm 5.3 \mathrm{~nm}$ ). When there was low dose of iron/alum salt
$(0.1 \mathrm{mM})$ in the feed, most alginate molecules could not be "captured" by the iron flocs or alum flocs. Thus, more alginate molecules still deposited onto the membrane surface and blocked membrane pores. However, more flocs formed gradually with increasing the dose of iron/alum salt, which could "capture" more alginate molecules. In comparison with the membrane flux decline caused by alginate coagulated with high dose of iron salt $(1.2 \mathrm{mM})$, the membrane flux decline caused by alginate coagulated with high dose of alum salt $(1.2 \mathrm{mM})$ was greatly decreased.

To understand the different membrane behavior caused by alginate in the presence of $1.2 \mathrm{mM}$ iron/alum salt, the properties of flocs were investigated. It is well known that the characteristics of flocs play an important role on reducing membrane fouling, due to the fact that the properties of the cake layer were determined by the properties of flocs [25]. The formation of flocs and their fractal dimensions were investigated in the jar test (Fig. 6). A rapid rise in the median size $\left(d_{50}\right)$ of both $1.2 \mathrm{mM}$ iron flocs and $1.2 \mathrm{mM}$ alum flocs were occurred during the rapid mixing/early flocculation period $(<3 \mathrm{~min})$, and the $d_{50}$ values of both iron salt and alum salt reached a maximum value after approximately 6 min (Fig. 6a). The $d_{50}$ of the alum flocs was smaller $(548 \pm 25 \mu \mathrm{m})$ than that of iron flocs $(786 \pm 39 \mu \mathrm{m})$. Furthermore, the fractal dimension of flocs formed by $1.2 \mathrm{mM}$ alum salt $\left(D_{\mathrm{f}}=\right.$ $2.71 \pm 0.07)$ was larger than that formed by $1.2 \mathrm{mM}$ iron salt $\left(\mathrm{D}_{\mathrm{f}}=\right.$ $2.48 \pm 0.03)$, resulting in a more compact cake layer formed by alum flocs (Fig. 2). According to Listiarini et al., the cake formation resistance $\left(1.73 \times 10^{13} \mathrm{~m}^{-1}\right)$ caused by alginate in the presence of alum $(30 \mathrm{mg} / \mathrm{L}$, calculated as $\mathrm{Al}$ ) was much lower than that in the absence of alum (a)

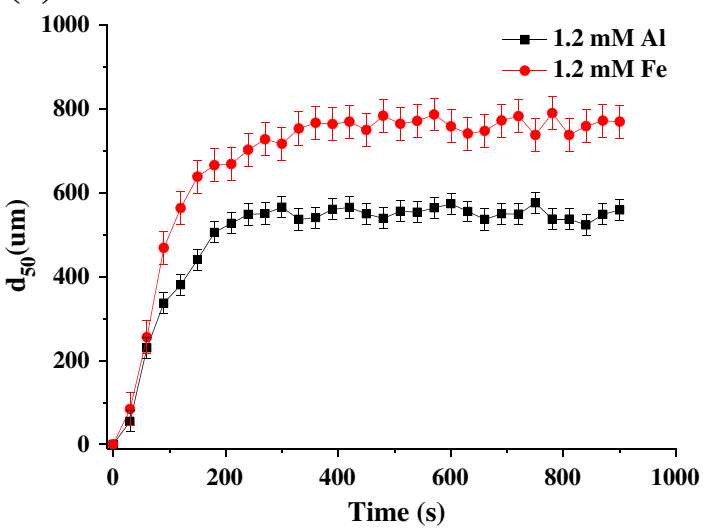

(b)

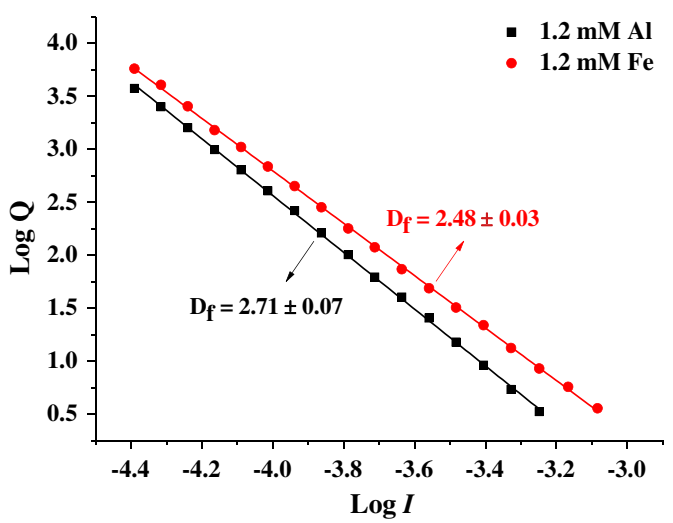

Fig. 6. Comparison of iron/alum floc characteristics at $\mathrm{pH}=7.0$ : (a) formation of flocs and (b) fractal dimension of flocs. 


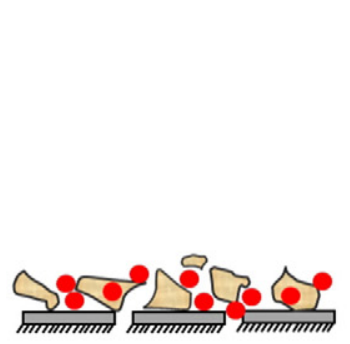

Low dose of iron

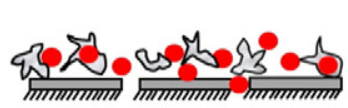

Low dose of alum
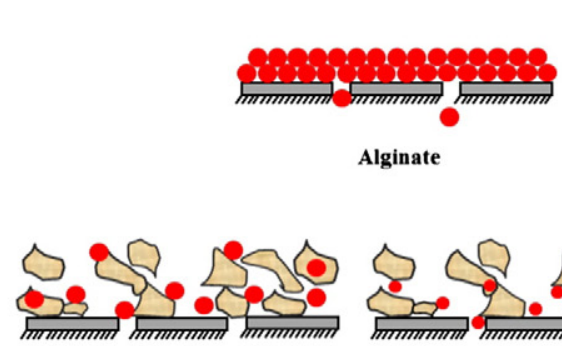

High dose of iron

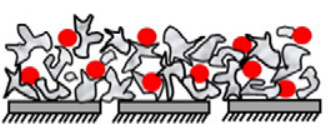

High dose of alum

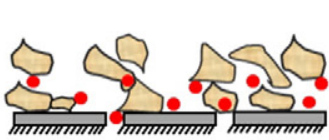

High dose of iron+ Sodium

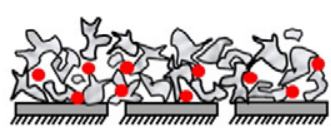

High dose of alum+ Sodium
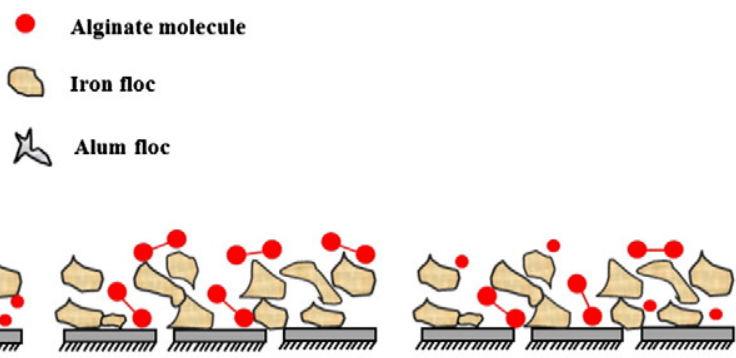

High dose of iron + Calcium

High dose of iron+ Sodium + Calcium
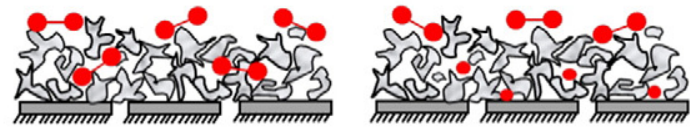

High dose of alum + Calcium High dose of alum + Sodium + Calcium

Fig. 7. Schematic diagram of the membrane fouling mechanism caused by alginate under different conditions at pH 7.0.

$\left(6.28 \times 10^{13} \mathrm{~m}^{-1}\right)$, which was conducted in nanofiltration [17]. As a result, membrane flux was significantly improved by high dose of alum salt.

In addition, the zeta potential of $1.2 \mathrm{mM}$ iron flocs was $2.32 \pm$ $0.57 \mathrm{mV}$ while that was $7.59 \pm 1.15 \mathrm{mV}$ of $1.2 \mathrm{mM}$ alum flocs. After coagulating with the $10 \mathrm{mg} / \mathrm{L}$ alginate, the zeta potential of $1.2 \mathrm{mM}$ alum flocs was $-16.58 \pm 1.13 \mathrm{mV}$, and that was $-20.44 \pm 2.21 \mathrm{mV}$ for the $1.2 \mathrm{mM}$ iron flocs. The zeta potential indicated that alum flocs could adsorb a little more alginate molecules during flocculation compared to that of iron flocs. Furthermore, the sedimentation rate of the $1.2 \mathrm{mM}$ iron flocs was much faster than that of the $1.2 \mathrm{mM}$ alum flocs after coagulation. Therefore, the chance of alginate molecules depositing onto the membrane surface or blocking into the membrane pores was much less in the presence of $1.2 \mathrm{mM}$ alum salt than that in the presence of $1.2 \mathrm{mM}$ iron salt. In other words, membrane flux decline caused by alginate coagulated with alum salt was significantly decreased compared to that coagulated with iron salt.

Lee et al. [9] showed that alginate molecules could become more coiled at high ionic strength due to the reduced interchain electrostatic repulsion. Thus, the flux decline caused by alginate in the presence of iron/alum salt with ionic strength was more serious than that without ionic strength because the chance of alginate molecules blocking the membrane pores was larger, especially for the less compact iron flocs. Lee et al. [6] and Nataraj et al. [8] demonstrated that calcium ions could bind with carboxylic groups, forming "bridges" between adjacent alginate molecules. As a result, when calcium ions and high dose of iron/alum salt were presented together in the solution, membrane flux decline was significantly decreased, of which a more compressible layer was formed on the membrane surface after "capturing" most alginate molecules during the filtration, especially for alum salt [17]. In addition, this formed cake layer reduced the chance of alginate molecules depositing onto the membrane surface or blocking into the membrane pores, leading to the membrane fouling reduced. When iron/alum flocs, ionic strength and calcium ions were all in the system, the flux decline caused by alginate under this condition was greater than that in the presence of iron/alum flocs and calcium ions, while smaller than that in the presence of the combination of iron/alum flocs and ionic strength. However, owning to the smaller average diameter, larger fractal dimension, and stronger adsorption capacity of alum flocs, the membrane fouling caused by alginate was less serious in the presence of alum flocs than that in the presence of iron flocs, whether ionic strength, calcium ions and their combinations were in the system or not. Detailed fouling mechanism was shown in Fig. 7.

\section{Conclusions}

Coagulation pre-treatment could enhance the performance of membrane filtration by decreasing the chance of pollutants getting to the membrane surface and blocking the membrane pores. Fouling caused by alginate coagulated with iron/alum salt on UF membrane was investigated with/without ionic strength, calcium ions and their combinations in the system. The overall findings of the study are as follows:

1. UF membrane fouling caused by alginate was significantly reduced only in the presence of high dose of iron/alum salt, due to most alginate molecules could still be adsorbed onto the membrane surface or blocked into the membrane pores with low dose of iron/alum salt in the solution.

2. Membrane flux decline was increased by increasing ionic strength in the presence of high dose of iron/alum salt while that was significantly decreased in the combination of calcium ions and high dose of iron/alum salt. When ionic strength and calcium ions were presented together with high dose of iron/alum salt, the flux decline caused by alginate was lower than that with only ionic strength and high dose of iron/alum salt, but higher than that with only calcium ions and high dose of iron/alum salt.

3. Alum salt behaved better than iron salt with/without ionic strength, calcium ions, and their combinations in the feed. The measured alginate concentration after filtration was correlated well with the flux decline. Membrane flux decline was much more decreased at coagulation conditions, which resulted in a lower concentration of alginate after filtration, especially in the combination of calcium ions and alum salt.

\section{Acknowledgments}

This work was supported by National Natural Science Foundation of China (Grants 51138008 and 51108444). Also some of this work was supported by the National Science \& Technology Project in Countryside (2012BAJ25B00).

\section{References}

[1] D. Jermann, W. Pronk, S. Meylan, M. Boller, Interplay of different NOM fouling mechanisms during ultrafiltration for drinking water production, Water Res. 41 (2007) 1713-1722. 
[2] L.Y. Ng, A.W. Mohammad, C.P. Leo, N. Hilal, Polymeric membranes incorporated with metal/metal oxide nanoparticles: a comprehensive review, Desalination 308 (2013) 15-33.

[3] W. Gao, H. Liang, J. Ma, M. Han, Z.L. Chen, Z.S. Han, G.B. Li, Membrane fouling contro in ultrafiltration technology for drinking water production: a review, Desalination $272(2011) 1-8$

[4] K. Katsoufidou, S.G. Yiantsios, A.J. Karabelas, Experimental study of ultrafiltration membrane fouling by sodium alginate and flux recovery by backwashing, J. Membr. Sci. 300 (2007) 137-146.

[5] C. Jarusutthrak, G. Amy, J.P. Croue, Fouling characteristics of wastewater effluent organic matter (EfOM) isolate on NF and UF membranes, Desalination 145 (2002) 247-255.

[6] S. Lee, M. Elimelech, Relating organic fouling to reverse osmosis membranes to intermolecular adhesion forces, Environ. Sci. Technol. 40 (2006) 980-987.

[7] M. Saraswathi, K.M. Rao, M.N. Prabhakar, C.V. Prasad, K. Sudakar, H.M.P. Naveen Kumar, M. Prasad, K.C. Rao, M.C.S. Subha, Pervaporation studies of sodium alginate (SA)/dextrin blend membranes for separation of water and isopropanol mixture Desalination 269 (2011) 177-183.

[8] S. Nataraj, R. Schomäcker, M. Kraume, I.M. Mishra, A. Drews, Analyses of polysaccharide fouling mechanisms during cross flow membrane filtration, J. Membr. Sci. 308 (2008) 152-161.

[9] S. Lee, W.S. Ang, M. Elimelech, Fouling of reverse osmosis membranes by hydrophilic organic matter: implication for water reuse, Desalination 187 (2006) 313-321.

[10] S. Lee, M. Elimelech, Salt cleaning of organic-fouled reverse osmosis membranes, Water Res. 41 (2007) 1134-1142.

[11] M.A. Zazouli, S. Nasseri, M. Ulbricht, Fouling effects of humic and alginate acids in nanofiltration and influence of solution composition, Desalination 250 (2010) 688-692.

[12] Y.N. Wang, C.Y. Tang, Nanofiltration membrane fouling by oppositely charged macromolecules: investigation on flux behavior, foulant mass deposition and solute rejection, Environ. Sci. Technol. 45 (2011) 8941-8947.

[13] C. Jarusutthirak, M. Supatpong, J. Ratana, Influence of inorganic scalants and natura organic matter on nanofiltration membrane fouling, J. Membr. Sci. 287 (2007) 138-147.

[14] S. Lee, J. Cho, M. Elimelech, A novel method for investigating the influence of feed water recovery on colloidal and NOM fouling of RO and NF membranes, Environ. Eng. Sci. 22 (2005) 496-509.

[15] G.T. Grant, E.R. Morris, D.A. Rees, P.J.C. Smith, D. Thom, Biological interactions between polysaccharides and divalent cations: the egg-box model, FEBS Lett. 32 (1973) 980-987.

[16] W.S. Ang, M. Elimelech, Protein (BSA) fouling of reverse osmosis membranes: implications for wastewater reclamation, J. Membr. Sci. 296 (2007) 83-92.

[17] K. Listiarini, W. Chun, D.D. Suna, J.O. Leckie, Fouling mechanism and resistance analyses of systems containing sodium alginate, calcium, alum and their combination in dead-end fouling of nanofiltration membranes, J. Membr. Sci. 344 (2009) 244-251.

[18] W.J.C.V.D. Ven, K.V.T. Sant, I.G.M. Punt, A. Zwijnenburg, A.J.B. Kemperman, W.G.J.V. derMeer, M. Wessling, Hollow fiber dead-end ultrafiltration: influence of ionic environment on filtration of alginates, J. Membr. Sci. 308 (2008) 218-229.
[19] A.J. deKerchove, M. Elimelech, Structural growth and viscoelastic properties of adsorbed alginate layers in monovalent and divalent salts, Macromolecules 39 (2006) 6558-6564.

[20] H.K. Shon, S. Vigneswaran, H.H. Ngo, R.B. Aim, Is semi flocculation effective as pretreatment to ultrafiltration in wastewater treatment, Water Res. 39 (2005) $147-153$.

[21] B.B. Lee, K.H. Choo, D. Chang, S.J. Choi, Optimizing the coagulant dose to control membrane fouling in combined coagulation/ultrafiltration systems for textile wastewater reclamation, Chem. Eng. J. 155 (2009) 101-107.

[22] Y. Wang, W.Z. Zhou, B.Y. Gao, X.M. Xu, G.Y. Xu, The effect of total hardness on the coagulation performance of aluminum salts with different Al species, Sep. Purif. Technol. 66 (2009) 457-462.

[23] H.C. Kim, J.H. Hong, S. Lee, Fouling of microfiltration membranes by natural organic matter after coagulation treatment: a comparison of different initial mixing conditions, J. Membr. Sci. 283 (2006) 266-272.

[24] E. Barbot, S. Moustier, J.Y. Bottero, P. Moulin, Coagulation and ultrafiltration: understanding of the key parameters of the hybrid process, J. Membr. Sci. 325 (2008) 520-527.

[25] W.Z. Yu, N. Graham, H.J. Liu, J.H. Qu, Comparison of $\mathrm{FeCl}_{3}$ and alum pre-treatment on UF membrane fouling, Chem. Eng. J. 234 (2013) 158-165.

[26] K. Konieczny, D. Sakol, J. Pronka, M. Rajca, M. Bodzek, Coagulation-ultrafiltration system for river water treatment, Desalination 240 (2009) 151-159.

[27] X.L. Qiao, Z.J. Zhang, N.C. Wang, W. Victor, L. Megan, C.S. Loh, N.T. Hing, Coagulation pretreatment for a large-scale ultrafiltration process treating water from the Taihu River, Desalination 230 (2008) 305-313.

[28] P. Jarvis, B. Jefferson, S.A. Parson, Breakage, re-growth, and fractal nature of natural organic matter flocs, Environ. Sci. Technol. 39 (2005) 2307-2314.

[29] W.Z. Yu, C.Z. Hu, H.J. Liu, J.H. Qu, Effect of dosage strategy on Al-humic floc growth and re-growth, Colloids Surf. A 404 (2012) 106-111.

[30] M. Dubois, K.A. Gilles, J.K. Hamilton, P.A. Robers, F.J. Smith, Colorimetric method for the determination of sugars and related substances, Anal. Chem. 28 (1965) 350-356.

[31] K. Kimura, Y. Hane, Y. Watanabe, G. Amy, N. Ohkuma, Irreversible membrane fouling during ultrafiltration of surface water, Water Res. 38 (2004) 3431-3441.

[32] W.R. Bowen, R.J. Cooke, Properties of microfiltration membranes: computer automated determination of the electrokinetic properties of polycarbonate membranes, J. Colloid Interface Sci. 141 (1991) 280-287.

[33] T. Windhues, W. Borchard, Temperature depending light scattering measurements of aqueous gelatin and alginate solutions and their mixtures, Eur. Polym. J. 38 (2002) 1219-1227.

[34] P.V.D. Brink, A. Zwijnenburg, G. Simth, H. Temmink, M.V. Loosdrecht, Effect of free calcium concentration and ionic strength on alginate fouling in cross-flow membrane filtration, J. Membr. Sci. 345 (2009) 207-216.

[35] F. Wang, V.V. Tarabara, Pore blocking mechanisms during early stages of membrane fouling by colloids, J. Colloid Interface Sci. 328 (2008) 464-469. 